\title{
Artigo
}

\section{Projeção, fragmentação e justaposição de processos Regionalismo pós-hegemônico, retorno do regionalismo aberto: a atualidade do regionalismo na America Latina e no Caribe}

\author{
Projection, fragmentation and juxtaposition of post-hegemonic regionalism, return to \\ opened regionalism: the present of regionalism in Latin America and Caribe \\ DOI: $10.5752 /$ P.1809-6182.2016v13.n1.p16
}

José Briceño Ruiz ${ }^{1}$

Recebido em: 12 de maio de 2016 Aprovado em: 13 de maio de 2016

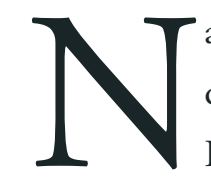
a realidade eu quero simplesmente compartilhar com vocês algumas ideias de qual é a situação atual da integração regional ou do regionalismo na America Latina. Quero começar pelo que entendo por regionalismo, de maneira breve por ser um tema de ampla discussão teórica (se regionalismo é sinônimo de integração regional, se há regionalismo ou integração na América Latina, etc. - o que acaba tornando a discussão um pouco estéril). Regionalismo para mim se refere a muitas coisas, a um processo diverso que cobre um âmbito geográfico, espacial, determinado, e nesse espaço geográfico podem acontecer processos de integração econômica, de integração política, de cooperação política, de cooperação econômica. Neste sentido, são esses processos de integração ou cooperação econômica e política que ocorrem em um ambiente geográfico especifico que podem ser chamados de regionalismo, especialmente quando é o resultado de acordos formais entre os Estados, pois si fossem interaçôes económicas ou da sociedade civil estaríamos no caso de um processo de regionalização. A categoria do regionalismo tem um valor explicativo muito maior do que integração regional em alguns casos - o que é importante notar dado que na América Latina há certa confusão com relação aos processos de integração regional, uma vez que muitos dos casos analisados não sáo processos de integração regional, mas sim processos de cooperação regional, como é o caso da União de Nações Sul-Americanas (UNASUL). Para mim UNASUL não é integração regional e sim cooperação regional. Ou seja, o regionalismo aparece como iniciativas de integração econômica e política - que não existe no caso da América Latina - ou de cooperação econômica e política.

\footnotetext{
1 Professor da Universidad de Los Andes, Venezuela. orcid.org/0000-0003-2710-4435. Este artigo é uma versão revisada de palestra proferida em 15 de Setembro de 2015, PUC Minas.

Tradução: Bárbara Lopes Campos.
} 
A grande questão é que nos últimos 25 anos, ou nas últimas décadas, a América Latina está passando por um processo de completa redefinição; quer dizer, de definição e redefinição, do que entende por regionalismo, de quais são as lógicas que devem impulsionar o regionalismo e o porquê do regionalismo. Podem-se perceber períodos onde se observa uma série de preceitos econômicos, políticos, técnicos e ideológicos significativos e importantes, que expressam interesses de grupos, visóes de mundo, etc. $\mathrm{O}$ primeiro período é a década de 1990, definida como a década do regionalismo aberto, que se mantém como hegemônico até por volta do ano de 2003. O segundo período é o regionalismo pós-liberal ou pós-hegemônico. E atualmente, a partir do ano 2013, estamos em uma etapa de redefinição, onde não está muito claro até onde vai o regionalismo. Alguns se perguntam se o que está havendo é um retorno ao regionalismo aberto, e por isso a terceira etapa aparece mais como uma pergunta, devido à incerteza do cenário vivido pela America Latina. Como definimos atualmente o regionalismo na America Latina? Regionalismo pós-liberal, pós-hegemônico ou regresso ao regionalismo aberto? Mais ainda, quais são suas consequências?

Retornemos ao primeiro período, conhecido como regionalismo aberto. $\mathrm{O}$ regionalismo aberto começa no final da década de 1980, quando os países da América Latina, forçados pela circunstância de crise profunda que viviam as economias da região, em função da impossibilidade de pagar suas dívidas (crises da dívida e do colapso do modelo de substituição de importações), optaram por um novo modelo de desenvolvimento, o Consenso de Washington. O Consenso de Washington parte do pressuposto do livre mercado como a maneira mais eficiente de impulsionar a economia e, como consequência, seria o mecanismo para a America Latina alcançar o desenvolvimento econômico. Essa ideia foi hegemônica na década de 1990, todos os países da America Latina e os governos da região, da esquerda ou da direita, optaram pelo Consenso de Washington e aderiram à ideia de que os mercados eram mais eficientes, de que os Estados eram ineficientes, de que o protecionismo era inadequado, e que livre comércio era o correto. $\mathrm{Na}$ Argentina os partidos de raízes nacionalistas como como o peronismo na era de Menem seguiram medidas do Consenso de Washington. No México, o Partido Revolucionário Institucional (PRI) adota Consenso de Washington. No Brasil, Fernando Henrique, que começa com uma proposta social democrata, opta pelo Consenso de Washington. A ideia era hegemônica e não só imperou nos projetos de desenvolvimento econômico nacional como impactou na maneira de entender o regionalismo e a integração e cooperação regional, a tal ponto que a Comissão Econômica para América Latina e o Caribe (CEPAL) publica um documento em 1994 que se chama regionalismo aberto na America Latina: a integração regional a serviço da transformação produtiva com equidade. A proposta seria um regionalismo aberto que não descriminaria o resto do mundo. Pode-se pensar em alguns indicadores que se alteram dependendo do período que se trata. Os indicadores seriam a lógica, a agenda e a modalidade da integração regional ou do regionalismo.

A lógica do regionalismo aberto era comercial na década do noventa. Regionalismo se entendia como livre comércio, simplesmente, para se inserir com eficiência num mundo globalizado. Seria uma resposta, em termos semelhantes, ao que estava ocorrendo na América do Norte, com os Estados Unidos, Canadá e México no Tratado Norte-Americano de Livre Comércio (NAFTA) ou Tratado de Libre Comercio de América del Norte (TLCAN). E o objetivo final era se desenvolver de maneira eficiente inseridos na economia mundial. A agenda neste caso era de integração profunda com a eli- 
minaçáo dos obstáculos ao comércio internacional de maneira rápida. Um exemplo concreto era a proposta de se criar, no âmbito do Mercosul, uma área de livre comércio em 5 anos. Neste quadro, novos elementos são incorporados nas negociaçóes comerciais - elementos estes que não faziam parte da agenda de integração das décadas anteriores -, como a regulamentação da propriedade intelectual, em particular direito de patentes, dos serviços, das compras públicas, temas ambientas, de trabalho, que passam a ser temas de discussáo regional e que são sensíveis para muitos países (como no caso do Brasil e África do Sul e a produção de medicamentos genéricos como essenciais para o combate de certas doenças, devido ao custo baixo se comparado aos produtos das multinacionais farmacêuticas). Dessa forma, esses temas são colocados como essenciais nas discussões sobre regionalismo, como quando os Estados Unidos defenderam a importância de se regulamentar os direitos de propriedade intelectual. Ainda em relaçấo à modalidade do regionalismo aberto, se mantém a ideia de integração Sul-Sul, ou seja, entre os países que possuem as mesmas condiçóes de desenvolvimento (como o caso do Mercosul), mas aparece também um novo tipo de integração conhecido como Norte-Sul, no caso de países desenvolvidos com países subdesenvolvidos (como no caso da interaçẫo entre Estados Unidos e México). Portanto, têm-se três ideias básicas hegemônicas identificadas no regionalismo aberto: a inserção internacional, a integração profunda e uma lógica às vezes Sul-Sul e às vezes Norte-Sul. O caso mais ambicioso do período foi a Área de Livre Comércio das Américas (ALCA).

A partir de 2003, a região mudou, com o surgimento de transformaçóes políticas, ideológicas, estratégicas e econômicas. As ideias de que as políticas de livre mercado eram o caminho do desenvolvimento passaram a ser questionadas, já que dois dos países mais importantes da região (Argentina e
Brasil), que haviam aderido a tais políticas econômicas orientadas para o mercado, entraram em crises. Neste contexto o regionalismo aberto começa a ser questionado, pois dois dos "melhores alunos" do Consenso de Washington entram em crise. A isso se acrescenta o giro político que ocorre na América Latina no período, com a ascensão de governos de esquerda e centro-esquerda que, apesar de apresentarem distintos elementos entre si, compartilham o fato de oporem ao Consenso de Washington. Formou-se, assim, um grupo de países com ideologia de centro-esquerda que rejeitavam as propostas do regionalismo aberto. Além disso, há o fracasso da ALCA, especialmente no contexto dos atentados de 11 de Setembro de 2001 e da securitização da agenda dos Estados Unidos, o que se refletiu em um desinteresse dos EUA pelo regionalismo e representou o colapso do que seria o exemplo do regionalismo liberal. Entra-se, assim, no período conhecido como regionalismo pós-liberal ou pós-hegemônico. Pessoalmente, acho que a expressão pós-hegemônico explica mais que pós-liberal, pois algumas das políticas que procuram-se implementar seriam muito mais próximas de um cenário pré-liberal (como o retorno do Estado que implicava o retorno de algumas propostas da velha CEPAL) do que pós-liberal. Neste sentido a expressão pós-hegemônico possui um valor explicativo maior, já que reflete o fato do período anterior ter sido dominado por uma hegemonia específica. No momento pós 2003, portanto, se tem uma variedade de concepçôes sobre regionalismo, significando o rompimento com a hegemonia anterior.

A lógica do regionalismo pós-hegemônico é contrária à noção de livre comércio. A ideia da UNASUL, por exemplo, não é uma proposta de livre comércio, mas sim de cooperação política, militar, promoção da infraestrutura, criação de um banco do sul (cooperação financeira) e cooperação na área da saúde. A agenda da integração pós-he- 
gemônica é a promoção de uma infraestrutura que una a América do Sul, como o programa brasileiro de infraestrutura regional sul-americana. Outro ponto importante da agenda da integração pós-hegemônica é a cooperaçẫo financeira - com a criação de um banco, por exemplo, para criar instâncias de financiamento alternativo (e complementar) às instituiçôes financeiras internacionais. Em relação à modalidade, na etapa pós-hegemônica, os países se opuseram à ideia de integraçáo Norte-Sul, o que se exemplifica no bloqueio das negociaçóes de um acordo de Associação Estratégica com a União Europeia o a crítica de ALCA por Chávez no período.

A partir de mais ou menos 2013, período demarcado pela morte de Chávez e a saída de Lula do poder, o regionalismo pós-hegemônico perdeu força. Porém, no período pós-hegemônico, o que se falava era sobre UNASUL, banco do sul, e criação até mesmo de grandes obras - como o gasoduto da América do Sul proposto por a Venezuela, por exemplo. Em suma: uma demonstração de que houve uma mudança no sentido da integração é o fato de que nem UNASUL, nem ALBA, nem a Comunidade de Estados Latino-Americanos e Caribenhos (CELAC) e nem mesmo o "novo Mercosul" se centraram na pauta do livre comércio; e esses processos de integraçáa e cooperaçáo levaram a novas formas econômicas, produtivas, sociais, políticas e estratégicas de regionalismo.

Agora, onde estamos neste momento? Há um consenso geral de que Dilma não possui o carisma que tinha Lula. Havia uma imagem internacional de Lula como um líder que conseguia projetar a região latino-americana - assim como também Chávez possuía uma liderança importante no período pós-hegemônico. É importante notar que também se tratava de um período de crescimento econômico dos países da região: Todos os países estavam crescendo devido ao "boom" das commodities por eles exportadas, e o dinheiro conseguido era usado no financiamento dos projetos pós-hegemônicos. Além disso, há o afastamento dos EUA nas questôes da regiáo após o 11 de Setembro de 2001. Não obstante, aos poucos a situação foi mudando. O que havia sido considerado o fracasso da ALCA e o fim da intervenção dos EUA na regiâo sofre uma mudança a partir do momento em que os EUA começam a fazer acordos bilaterais com os países da região que considerava estratégicos (Colômbia, Chile, Peru e América Central). Além disso, os EUA começam a negociar também grandes acordos regionais, como a Parceria Transatlântica, que une os EUA com a União Europeia em uma grande aliança de comércio, e oTratado Transpacífico, que une EUA com o Japão, países sul-asiáticos e do Pacífico e alguns países da América do Sul. Assim, a estratégia dos EUA muda e um dos seus objetivos é se contrapor à China - mudança esta com impactos significativos para a América Latina. Outra mudança importante é a mudança dos preços das commodities da região, gerando uma série de problemas econômicos, como problemas fiscais, de câmbio, etc. Neste contexto, os governos de esquerda começam a serem questionados devido às dificuldades que passam a enfrentar.

Neste momento de questionamento devido às mudanças e transformaçōes, a estratégia do regionalismo aberto começa a ser resgatada por alguns, até mesmo esquerdistas, o que é exemplificado na Aliança para o Pacífico. Se analisarmos a partir dos indicadores anteriores, a Aliança possui basicamente as mesmas características das estratégias de regionalismo da década de 1990. Qual é a lógica e o objetivo final? A inserção internacional e o livre comercio. Qual é a agenda? A integração profunda na área comercial que não foi alcançada anteriormente (como integração da bolsa de valores e mercados financeiros). E qual é a modalidade? No fim das contas, é uma modalidade de integração sul-sul mas visa negociar com China e países da Ásia, sendo uma inte- 
ração Norte-Sul (países desenvolvidos com países em desenvolvimento). Portanto, estamos regressando ao regionalismo aberto. Não tenho a última palavra e são eventos que ainda estáo acontecendo. Isso irá depender se haverá ou não impeachment contra a Dilma e suas consequências; se a economia brasileira irá se recuperar em 2017 ou 2019. Irá depender de como - e se - o chavismo será derrotado na Venezuela em votaçóes para o parlamento e se no ano 2016 avançara a proposta de um referendum para destituir ao Maduro. Irá depender de quem sucederá no Equador. Irá depender do rumo estratégico seguido pela Argentina daqui para frente. E de outra série de questóes. Mas o que se tem é que o regionalismo pós-hegemônico neste momento está sendo fortemente golpeado por movimentos que buscam restaurar a lógica do regionalismo aberto. Isto é o que temos de concreto no momento.

O que temos são lógicas distintas de ação e um grupo de países que possuem uma inspiração pós-hegemônica, como Venezuela, Brasil e Argentina, nas quais as políticas de integração tem uma base pós-hegemônica; e países que tem políticas com uma base mais liberal, como Colômbia, Chile, México. Há, então, projetos de integração com lógicas distintas. Temos UNASUL, Aliança para o Pacífico, Mercosul e Alba, que são totalmente distintos. Vejamos apenas três exemplos. A Aliança para o Pacífico é absolutamente neoliberal, é o regionalismo aberto quase puro. O Mercosul é uma mescla entre o regionalismo aberto com algumas novas políticas de integração social e política. E a Aliança Bolivariana para os Povos da Nossa América (ALBA) é um regionalismo anti-imperialista. São três modelos de regionalismo completamente distintos, que se contradizem. Portanto, a América Latina tem um sério problema em relação ao regionalismo, tanto na dimensão econômica quanto na política, e há uma série de projetos que estão justapostos. $\mathrm{O}$ regionalismo na América Latina parece um prato de espaguete, difícil de lidar. Olhando apenas para os projetos econômicos, por exemplo, temos:

- a ALBA, que representa a parte mais radical, anti-sistêmica, anti-imperialista, anti-estadunidense e anti-capitalista do regionalismo;

- o Mercosul, que é um projeto revisionista, pois mantém o livre comércio mas possui políticas típicas de governos de esquerda em matéria social, produtiva e de cooperação política; e - a Aliança para o Pacífico é um processo liberal. Adicionando essas questôes, o prato fica ainda mais complicado. Há ainda, porém, outro fator a ser levado em consideração: existem projetos de integração na regiấo que não são econômicos, como a Associação dos Estados do Caribe, a UNASUL, a OEA e a CELAC, por exemplo.

Portanto, a integração na América Latina passa por um momento complexo, integração esta com tanta diversidade e tanta justaposiçáo, tendo até mesmo lógicas contraditórias. Uma visão pessimista é que essa diversidade vai levar a uma fragmentação de instituiçôes, já que não seria possível realizar uma aproximação entre ALBA e a Aliança para o Pacífico, uma vez que suas lógicas de política exterior são contraditórias (anti-americano/pró-americano, anti-liberal/pró-liberal). Assim, observar-se-ia um complexo de regimes em relação a essa situação do regionalismo na América Latina. Ou seja, há muitos regimes internacionais sobre o mesmo tema, regulando-o. Há uma justaposição de regimes horizontais e um complexo de regimes que não são hierarquizados (não há primazia de um sobre o outro). Isso pode gerar regimes com regulamentaçóes contraditórias, dando origem talvez a uma situação de troca de regimes pelos países em momentos oportunos. Por exemplo, se parecer melhor à Bolívia buscar financiamento para seu projeto de desenvolvimento com um país mais próximo a ela, pode levá-la a buscar financiamento com a ALBA e 
não com o Banco do Sul. A consequência disso é o "fórum shopping", onde se participa dos fóruns em que se conseguem as coisas de maneira mais fácil, dando origem a um processo de "shifting", ou seja, mudança de regimes de maneira oportunista. Neste sentido, a tendência seria a de que os problemas de ação coletiva dos projetos regionalistas se aprofundassem, afetando, desta forma, a produção e a solidariedade regional. Assim, o enfoque pessimista é que essa divisão entre países a favor do regionalismo aberto e países a favor do regionalismo pós-hegemônico criaria regimes de integração justapostos que afetariam o objetivo último de consolidar a unidade regional.

Outra possibilidade é a imagem positiva. Neste caso, a justaposição de regimes não é vista como um problema, pois representa uma lógica de geometria variável, na qual os países participam dos processos e das iniciativas que lhes interessam; e os que não lhes interessam não participam. O Chile, por exemplo, pode participar do livre comércio da Aliança para o Pacifico, sem precisar se comprometer com uma aliança aduaneira do Mercosul. Portanto, ser membro de vários processos não seria um problema em si - o que náo elimina o problema da criação de regimes contraditórios. Para terminar, há uma enorme diversidade no regionalismo da America Latina hoje em dia. Há a retórica de uma unidade latino-americana, mas que neste cenário não parece ser muito acessível. Parece, sim, que está havendo uma aproximação de países em grupos que tem visōes comuns e que se afastam de outros países. Assim, a ideia de um espaço comum latino-americano estaria se perdendo. Neste contexto, uma última pergunta é a seguinte: A CELAC seria uma espaço suficientemente complexo e importante para assumir a ideia de unidade latino-americana? É só isso.

Muito obrigado. 